\title{
HAM/TSP in relatives of HAM/TSP cases and in relatives of asymptomatic HTLV-1 carriers
}

Carolina Alvarez $z^{1,2^{*}}$ Kristien Verdonck ${ }^{1,3}$, Martín Tipismana ${ }^{1,4}$, Michael Talledo ${ }^{1}$, Jason Rosado ${ }^{1}$, Daniel Clark, Johan Van Weyenbergh ${ }^{2,6}$, Anne-Mieke Vandamme ${ }^{1,7}$, Eduardo Gotuzzo ${ }^{1,4}$

From 16th International Conference on Human Retroviruses: HTLV and Related Viruses

Montreal, Canada. 26-30 June 2013

To assess the hypothesis that HTLV-1-associated myelopathy/tropical spastic paraparesis (HAM/TSP) runs in families, we compared the frequency of HAM/ TSP among HTLV-1-positive relatives of HAM/TSP patients with the frequency of HAM/TSP among HTLV1-positive relatives of asymptomatic HTLV-1 carriers. We reviewed available information at the Instituto de Medicina Tropical Alexander von Humboldt in Lima (period 1990-2012). Index cases with HAM/TSP were defined as unrelated, HTLV-1-positive patients with a clinical diagnosis of HAM/TSP for whom HAM/TSP was the motive for HTLV-1 testing and who brought $\geq 1$ relative (blood relatives and/or partners) for HTLV-1 testing. Asymptomatic index cases were defined as unrelated, asymptomatic HTLV-1 carriers who were tested for HTLV-1 as candidate blood donors and brought $\geq 1$ relative for screening. In the family studies of 334 index cases with HAM/TSP, 1124 relatives were tested, 318/1124 (28\%) were HTLV-1 positive, and 30/318 (9\%) had HAM/TSP. In the family studies of 230 asymptomatic index cases, 544 relatives were tested, 204/544 (38\%) were HTLV-1 positive, and $15 / 204$ (7\%) had HAM/TSP. We classified the relatives in groups based on sex and age. HAM/TSP frequency increased with age and was higher in women than in men. We found no significant differences in HAM/TSP frequency between relatives of HAM/TSP index cases and relatives of asymptomatic index cases. In total, there were 21 families with 2 HAM/TSP cases, 4 families with 3 HAM/ TSP cases, and 1 family with 5 HAM/TSP cases. This analysis approach suggests that HAM/TSP usually affects isolated people, but that in some, particular families, HAM/ TSP clusters can occur.

\footnotetext{
* Correspondence: carolina.alvarez@upch.pe

'Instituto de Medicina Tropical Alexander von Humboldt, Universidad

Peruana Cayetano Heredia, Lima, Peru

Full list of author information is available at the end of the article
}

\section{Authors' details}

'Instituto de Medicina Tropical Alexander von Humboldt, Universidad Peruana Cayetano Heredia, Lima, Peru. ${ }^{2}$ Rega Institute for Medical Research, Katholieke Universiteit Leuven, Leuven, Belgium. Institute of Tropical Medicine, Antwerp, Belgium. ${ }^{4}$ Facultad de Medicina Alberto Hurtado, Universidad Peruana Cayetano Heredia, Lima, Peru. ${ }^{5}$ Laboratorios de Investigación y Desarrollo, Universidad Peruana Cayetano Heredia, Lima, Peru. ${ }^{6}$ Gonçalo Moniz Research Center, Oswaldo Cruz Foundation, Salvador-Bahia, Brazil. ${ }^{7}$ Instituto de Higiene e Medicina Tropical, Universidade Nova de Lisboa, Lisboa, Portugal.

Published: 7 January 2014

\section{doi:10.1186/1742-4690-11-S1-P37}

Cite this article as: Alvarez et al:: HAM/TSP in relatives of HAM/TSP cases and in relatives of asymptomatic HTLV-1 carriers. Retrovirology 2014 11(Suppl 1):P37.
Submit your next manuscript to BioMed Central and take full advantage of:

- Convenient online submission

- Thorough peer review

- No space constraints or color figure charges

- Immediate publication on acceptance

- Inclusion in PubMed, CAS, Scopus and Google Scholar

- Research which is freely available for redistribution

Submit your manuscript at www.biomedcentral.com/submit
() Biomed Central 